\title{
Simultaneous Effect of Temperature And Time of Deacetylation On Physicochemical Properties of Glucomannan
}

\author{
Dyah Hesti Wardhani ${ }^{*, 1}$ \\ Fatoni Nugroho ${ }^{1}$ \\ Nita Aryanti ${ }^{1}$ \\ Aji Prasetyaningrum ${ }^{1}$ \\ 1 Chemical Engineering Department, Faculty of Engineering, Diponegoro University, Jl. Prof. \\ Sudarto, Tembalang-Semarang, 50275, Telp/fax: (024)7460058/(024)76480675 \\ *e-mail: dhwardhani@che.undip.ac.id
}

The presence of acetyl group in the backbone of water-soluble glucomannan is responsible for its solubility. This solubility requires being modified to support glucomannan application as an encapsulant. Removing the group by deacetylation reduces the solubility. This work was aims to study simultaneous effect of temperature and time of deacetylation on glucomannan physicochemical properties. The deacetylation was conducted in ethanol using $\mathrm{Na}_{2} \mathrm{CO}_{3}$ at various times $(2,4,8,16,24$ and $28 \mathrm{~h}$ ) and temperatures (room temperature, 40,50 , and $60^{\circ} \mathrm{C}$ ). The deacetylated samples were subject to degree of deacetylation (DD) as well as solubility and swelling analysis in $\mathrm{pH} 1.2$ and 6.8. DD was in positive correlation with deacetylation time and temperature. The solubility of the deacetylated glucomannan at both $\mathrm{pHs}$ decreased along with the deacetylation time. A reverse trend was found for swelling determination at both pHs. Increasing deacetylation temperature showed a positive impact in swelling determination but not occuring on the solubility. Interestingly, the swelling and solubility were lower at $\mathrm{pH} 1.2$ than those at $\mathrm{pH}$ 6.8. These results showed physicochemical of deacetylated glucomannan was $\mathrm{pH}$ sensitive, hence have a potency as an excipient of controlledrelease drug delivery system.

Keywords: deacetylation, $\mathrm{Na}_{2} \mathrm{CO}_{3}$, glucomannan, solubility, swelling

\section{INTRODUCTION}

Glucomannan is a non-ionic linear heteropolysacharides consist of Dglucopyranose and D-mannopyranose. Acetyl groups are attached at C-6 position on average every 9-19 sugar units (Takigami 2000). This hydrophilic and biodegradable compound is known as one of the highest viscosity copolymers and commonly used as functional food material. It has an extraordinary water binding capacity and able to absorb over 100 times of its dry weight (Herranz et al. 2013).

The ability of glucomannan to form gel and its high viscosity has been an interest for application in foods and pharmaceutical areas including controlled release excipient (Jin et al. 2014). However, its high water- 
2 Simultaneous Effect Of Temperature And Time Of Deacetylation On Physicochemical Properties Of Glucomannan

solubility has been limiting its application as the excipient. The acetyl groups are responsible for its solubility, hence inhibit its gelation and coating ability (Gao and Nishinari 2004).

The presence of the acetyl group restricts formation of hydrogen bond intra and inter glucomannan molecules (Wardhani et al. 2016). In order to improve the glucomannan performance as the controlled drug release, the acetyl needs to be removed by using alkali. This modification transforms the ability to build junction zones through hydrogen bonding, dipole-dipole etc. The removal of acetyl forms a thermoreversible elastic gel (Du et al. 2012, Herranz et al. 2013). The gel formation facilitates modified glucomannan in application as excipient of drug (Zhang et al. 2014). Extensive studies have been conducted in gelation mechanism of deacetylated glucomannan (DGM). This DGM has been attempted to be applied in sausage \& seafood product (Solo-de-Zaldivar et al. 2014), wound dressing (Huang et al. 2015) and DNA excipient (Wen et al. 2008).

Porang tuber (Amorphophallus oncophyllus) is known as an excellent local source of glucomannan which grown commonly on the border of Indonesia forest. This tuber is underutilized for direct human consumption due to the calcium oxalate content (Harmayani et al. 2014). Modification of glucomannan of $A$. oncophyllus and its properties was still limitedly explored. Wardhani et al. (2017) has reported significant effect of variables on the deacetylation. This study aimed to study simultaneous effect of temperature and time deacetylation on the degree of deacetylation, solubility and swelling characteristics of DGM. Since DGM has potential as a drug excipient, hence the characteristics of DGM were determined in solution which represents the $\mathrm{pH}$ of digestive system.

\section{MATERIAL AND METHODS}

\section{Materials}

Glucomannan of Amorphophallus oncophillus was obtained from Nganjuk, East Java (91\%). Ethanol (96\%), $\mathrm{HCl}$, $\mathrm{Na}_{2} \mathrm{CO}_{3}$, and $\mathrm{KOH}$ were bought from Merck, Indonesia.

\section{Deacetylation Process}

Deacetylation was conducted following the method of Du et al. (2012). Glucomannan (10 g) was dissolved in 100 $\mathrm{ml}$ ethanol (75\%) before reacted with $\mathrm{Na}_{2} \mathrm{CO}_{3}(0.4 \mathrm{M}, 100 \mathrm{ml})$. The suspension was magnetically stirred at $300 \mathrm{rpm}$. After finishing the reaction, the suspension was filtered to collect the solid part which then dried subsequently. The deacetylation was conducted at various temperatures (room temperature, 40,50 , and $60^{\circ} \mathrm{C}$ ). Each of the temperatures was run at different times $(2$, $4,8,16,24$ and $28 \mathrm{~h}$ ). The dried samples were washed three times with $50 \mathrm{ml}$ ethanol (50, 70 and 96\%). After drying, the samples were subject to $D D$, solubility and swelling determination.

\section{Deacetylation Degree}

Deacetylation degree (DD) was determined according to the method of Zhang et al. (2015). Dried sample of deacetylated glucomannan was placed in erlenmeyer with $10 \mathrm{ml}$ ethanol (75\%). After 
stirring at $40^{\circ} \mathrm{C}$ for $30 \mathrm{~min}, \mathrm{KOH}$ was added $(0.5 \mathrm{M}, 5 \mathrm{ml})$. The excess of $\mathrm{KOH}$ was titrated with $\mathrm{HCl}(0.1 \mathrm{M})$ using phenolphthalein as an indicator. A blank was also prepared in parallel. The content of acetyl $\left(\omega_{0}\right)$ was calculated according to the equation [1].

$$
\omega 0=\frac{(V 2-V 1) x N H C l x \text { Macetyl }}{m s} 100 \%
$$

where $V_{1}$ and $V_{2}$ are the volume of $\mathrm{HCl}$ for titration the sample and blank in liter, respectively, $\mathrm{NHCl}$ is the normality of $\mathrm{HCl}$, Macetyl is the molecular weight of acetyl (43 $\mathrm{g} / \mathrm{mol}$ ) and $m s$ is the mass of sample $(\mathrm{g})$. DD was calculated following the formula [2]:

$$
D D=\frac{\omega 0-\omega}{\omega 0} \times 100 \%
$$

where $\omega_{0}$ and $\omega$ are the acetyl content in native glucomannan and in partially deacetylated sample, respectively.

\section{Solubility and Swelling Determination}

DGM was subject to solubility and swelling determination, following the method of Wardhani et al. (2017) for solubility and Daramola and Osanyinlusi (2006) for swelling. These determination were conducted in $2 \mathrm{pHs}$ e.g. 1.2 and 6.8. DGM $(0.1 \mathrm{~g})$ was dissolved in $10 \mathrm{ml} \mathrm{HCl}$ solution $(\mathrm{pH}$ 1.2) and phosphate buffer solution $(\mathrm{pH} 6.8)$ at $60^{\circ} \mathrm{C}$ for $30 \mathrm{~min}$. The supernatant and the pasta were collected and the weights were recorded after centrifuging at $4000 \mathrm{rpm}$ for $20 \mathrm{~min}$. The supernatant and the paste were oven dried and weight afterward.

$$
\begin{aligned}
& \% \text { solubility } \\
& =\frac{\text { Weight of dried supernatant }}{\text { Weight of supernatan }}
\end{aligned} 100 \%
$$

$$
\text { swelling }=\frac{\text { weight of paste }}{\text { weight of dried paste }}
$$

\section{RESULT AND DISCUSSION}

In this work, glucomannan was deacetylated using $\mathrm{Na}_{2} \mathrm{CO}_{3}$ at various temperatures (room temperature, 40, 50, and $60^{\circ} \mathrm{C}$ ). Each of the deacetylation temperatures was conducted at different times $(2,4,8,16,24$, and $28 \mathrm{~h})$. The result was subject to $D D$, solubility and swelling index. These analysis were determined at $\mathrm{pH} 1.2$ and 6.8. These $\mathrm{pHs}$ were selected to represent the $\mathrm{pH}$ of digestive system in the stomach and intestine (Beasley et al. 2015).

\section{The Deacetylation Degree (DD)}

The effect of temperature and time of deacetylation on DD of glucomannan is presented at Figure 1. Both variables showed a favorable on increasing DD. Higher temperature provides more energy to release acetyl (Wardhani et al. 2016). It also gives an energy for molecules to have a faster movement which subsequently results in more collision among them. This condition facilitates penetration into internal macromolecules and accelerate attacking other molecules (Li et al. 2014).

Deacetylation glucomannan as a function of time consists of two stages. The rapid decrease observed in the first hour when glucomannan cleavages into products followed by a slower rate degradation (Jin et al. 2014). Prolonging deacetylation period allows the higher possibility of reactants to collide each other. A significant improvement of DD was observed only at early room temperature reaction. Other than that 
4 Simultaneous Effect Of Temperature And Time Of Deacetylation On Physicochemical Properties Of Glucomannan

variable, the DD increased gradually along the deacetylation time. Li et al. (2014) suggested that deacetylation was a nucleophilic substitution reaction which not only depends on the reactant concentration but also concentration the product. After the reaction conducted for certain time, the number of acetyl groups available for reaction dropped. This condition led to slow down the reaction.

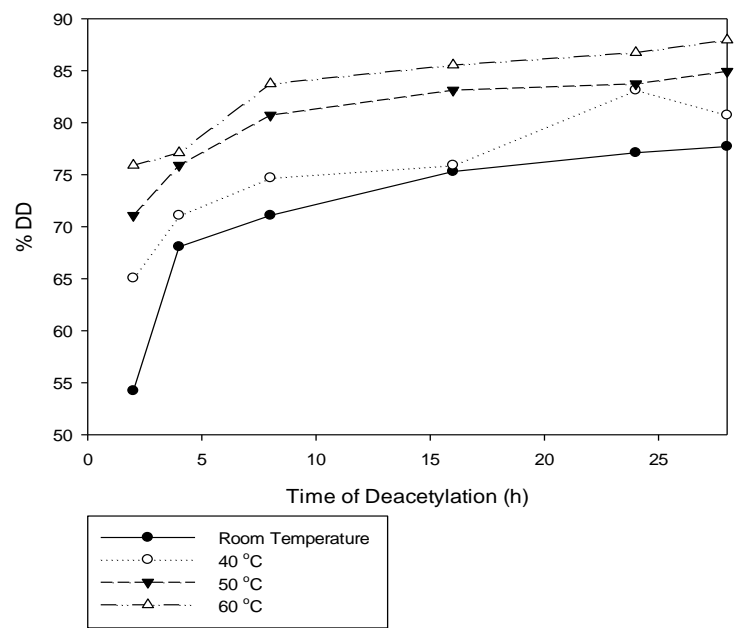

Fig. 1: The effect of deacetylation time and temperature on the deacetylation degree of glucomannan

It was hard to replace the whole acetyl

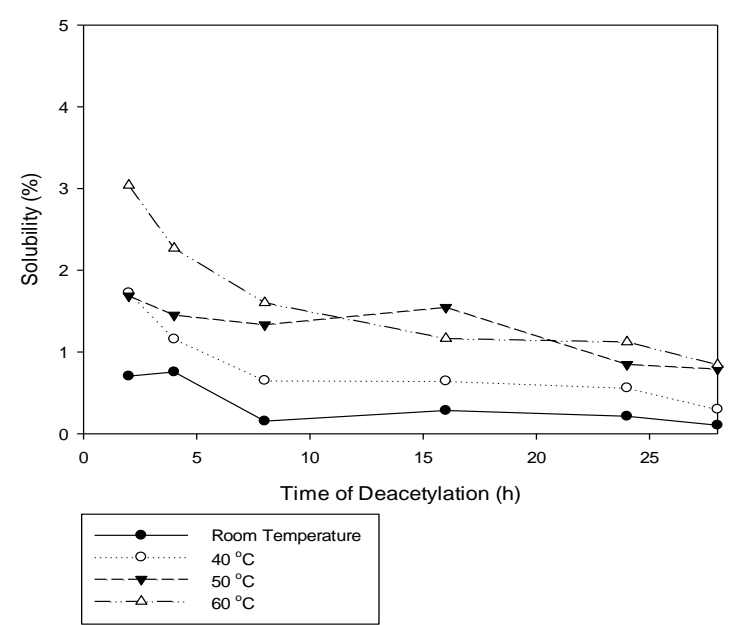

group and gain $100 \%$ DD. Extending the period of deacetylation over $16 \mathrm{~h}$ did not influence the DD significantly. The highest DD (87.95\%) was obtained after deacetylation at $60^{\circ} \mathrm{C}$ for $28 \mathrm{~h}$, which was still far from the total acetyl removal. Li et al. (2014) found 92\% DD after $72 \mathrm{~h}$ deacetylation. They reported all the acetyl was still hardly removed unless the excess of alkali was added in which molar ratio between glucomannan and $\mathrm{Na}_{2} \mathrm{CO}_{3}$ is $57: 1$. Similar effect of deacetylation time on DD was reported by Cho et al. (2000). These deacetylations resulted the $\mathrm{DD}$ in the range of $54.22-87.95 \%$ which was quite similar with the result of Li et al. (2014) who found 83\% DD for deacetylation glucomannan using $\mathrm{Na}_{2} \mathrm{CO}_{3}$ at $50^{\circ} \mathrm{C}$ for $24 \mathrm{~h}$.

\section{Glucomannan Solubility}

Deacetylation of glucomannan by removing the acetyl groups using $\mathrm{Na}_{2} \mathrm{CO}_{3}$ resulted in modification of its physicochemical properties. The effect of deacetylation time and temperature on DGM solubility was determined in $2 \mathrm{pHs}$ i.e. 1.2 and 6.8 (Figure 2). Figure 2 shows

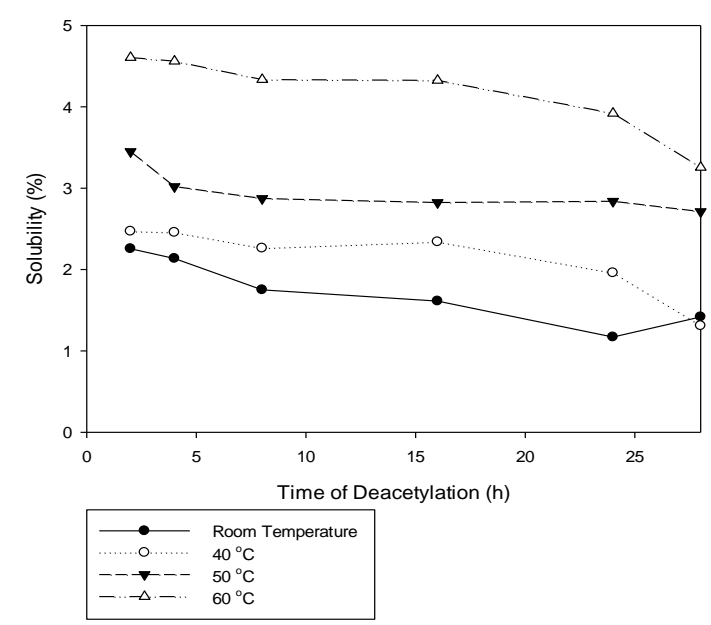

Fig. 2: The effect of deacetylation time and temperature on solubility of DGM at pH 1.2 (left) and $\mathrm{pH} 6.8$ (right) 

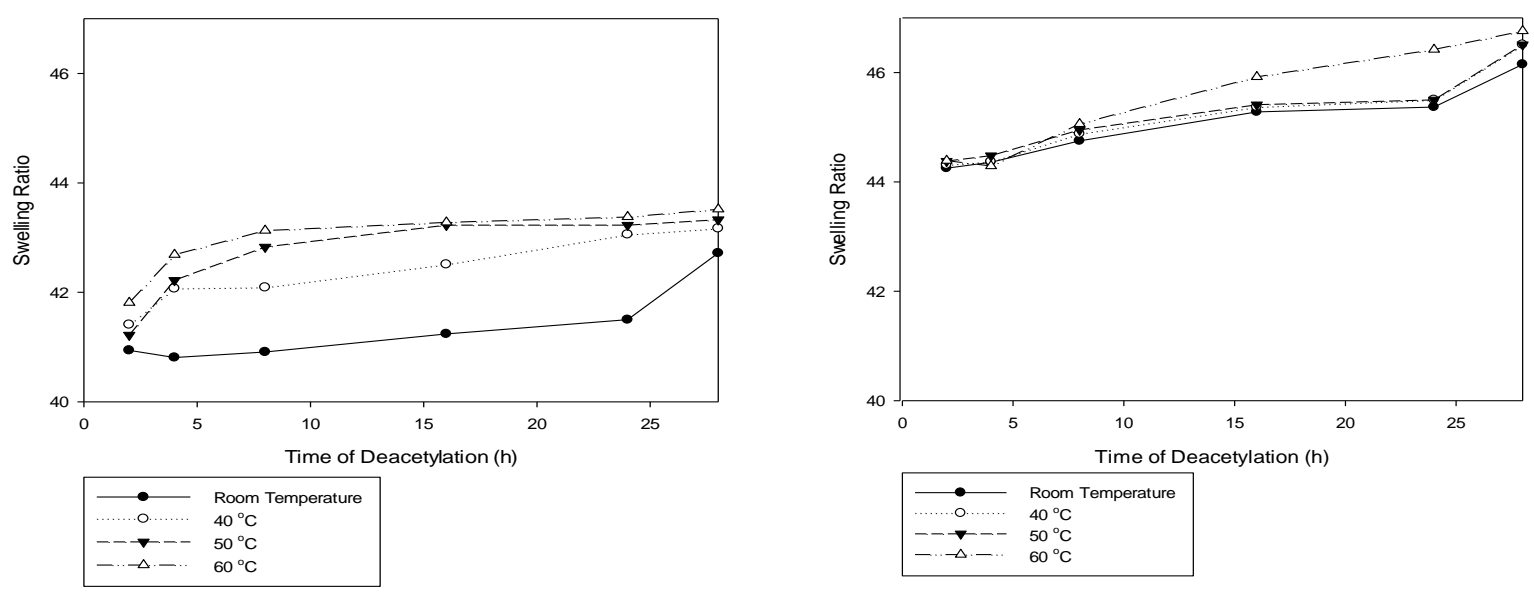

Fig. 3: The effect of deacetylation time and temperature on swelling index of $D G M$ at $p H$ 1.2 (left) and $\mathrm{pH} 6.8$ (right).

deacetylation reduced the solubility of glucomannan. Extending deacetylation led to reducing the solubility of DGM gradually. Interestingly, DGM of higher deacetylation temperature has higher solubility. Solubility of DGM in $\mathrm{pH} 1.2$ was lower than $\mathrm{pH}$ 6.8. The range of solubility of DGM in $\mathrm{pH} 1.2$ and 6.8 was $0.103-3.03 \%$ and $1.42-4.61 \%$, respectively.

Various effects of DD on solubility have been reported. Chen et al. (2011) and Du et al. (2012) found solubility of DGM was insignificantly change up to $52 \%$ of DD. However, the solubility decreased significantly over $52 \%$ of DD. Similar phenomenon was reported by $\mathrm{Li}$ et al. (2014) which found dropped of solubility on higher DD than $60 \%$. Base on our experiment results, we considered that the solubility of DGM partly due to effect of acetyl group removal (Wardhani et al. 2017). However, deeper study should be conducted to deliberate other factors involved in the solubility of DGM.

\section{Glucomannan Swelling}

Basically, swelling property of a material refers to the case when water molecules enter the material molecules and bind with the hydrophilic groups in the material molecules. Hence, swelling depends on the hydrophilic group of the molecules and intermolecular force (Wenling et al. 2005). The effect of deacetylation time and temperature on the glucomannan swelling at 2 (two) different pHs (1.2 and 6.8) is presented in Figure 3. These two $\mathrm{pH}$ are represented the free-acidity condition in the digestive tract particularly in stomach and intestine (Beasley et al. 2015).

In general, Figure 3 describes increasing deacetylation temperature allow DGM to have higher swelling index. Extending deacetylation time leads to improve swelling index. The swelling process of DGM consists of 2 stages, i.e., the breakage of inter-molecular hydrogen bonds of DGM followed by developing the hydrogen bonds between DGM and the water molecules. After deacetylation, less acetyl residues were available in the DGM. This indicated that DGM has more opportunities to form inter-molecular hydrogen bonds. Higher DD exhibits higher stability of DGM 
6 Simultaneous Effect Of Temperature And Time Of Deacetylation On Physicochemical Properties Of Glucomannan

due to stronger hydrogen bonds formed with water (Pan et al. 2011).

Deacetylation reduced steric hindrance and lead to increase DGM interaction (Huang et al. 2015). However, over interaction could facilitate reducing the number of site for water sorption. Chen et al. (2011) observed slightly swelling of DGM when DD over 80\%. Jin et al. (2015) reported moisture absorption of DGM film increases with DD due to greater exposure of $\mathrm{OH}$ group which enhance binding to more water through hydrogen bonding, but extending DD over $52 \%$ reduce the absorption. Moreover, water absorption also affected by the primary structure, long-range structure and condensed states of the polymers (Jin et al. 2015).

DGM has higher swelling in $\mathrm{pH} 6.8$ ( 44.25-46.76\%) than in $\mathrm{pH} 1.2$ (40.94$43.52 \%)$. Wen et al. (2009) stated that the higher the $\mathrm{pH}$ of swelling analysis, the higher the swelling value. It is due to the higher molecular interaction occurs in the higher $\mathrm{pH}$. The higher swelling value makes the glucomannan form gel well. Hydrogen bonding is considered as the main contributor in gel formation, which influences the interaction of hydroxyl groups of sugar residues in DGM.The hydrophobic interactions, on the other hand, result from the repulsive force exerted by the aqueous environment (Wen et al. 2009). Difference swelling sensitivity of DGM support for its application as excipient of controlled-release drug.

\section{CONCLUSION}

DD was in line with deacetylation time and temperature. Solubility of the DGM decreased along with the deacetylation time. A reverse trend was found for swelling determination at both $\mathrm{pHs}$. Interestingly, the swelling and solubility were lower at $\mathrm{pH}$ 1.2 than those at $\mathrm{pH}$ 6.8. These results showed functional properties of DGM was $\mathrm{pH}$-sensitive. This property showed a potency of DGM as an excipient of controlled-release drug delivery system.

\section{ACKNOWLEDGEMENT}

This research was funded by Non-APBN DPA SUKPA LPPM UNDIP through International Publication Research Scheme [Project Number DIPA-27653/UN7.5.1/PG/2017, Date 23 March 2017].

\section{REFERENCES}

1. Beasley, D.E., Koltz, A.M., Lambert, J.E., Fierer, N., Dunn, R.R. (2015). The Evolution of Stomach Acidity and Its Relevance to the Human Microbiome, PLoS one, 10(7), pp 1 - 12.

2. Chen, J., Li, J., and Li, B. (2011). Identification of molecular driving forces involved in the gelation of konjac glucomannan : Effect of degree of deacetylation on hydrophobic association, Carbohydrate Polymers, 86(2), pp 865 - 871.

3. Cho, Y.W., Jang, J., Park, C.R., and Ko, S.W. (2000). Preparation and Solubility in Acid and Water of Partially Deacetylated Chitins, Biomacromol, 1, pp 609 - 614.

4. Daramola, B., and Osanyinlusi, S.a. (2006). Investigation on modification of cassava starch using active components of ginger roots ( Zingeiber officianale Roscoe), African Journal of 
Biotechnology, 5 (10), pp 917 - 920.

5. Du, X., Li, J., Chen, J., and Li, B. (2012). Effect of Degree of Deacetylation on Physicochemical and Gelation Properties of Konjac Glucomannan, Food Research International, 46 (1), pp $78-270$

6. Gao, S., and Nishinari, K. (2004). Effect of Deacetylation Rate on Gelation Kinetics of Konjac Glucomannan, Colloids and Surfaces. B, Biointerfaces, 38 (3-4), pp 49 - 241

7. Harmayani, E., Aprilia, V., and Marsono, Y. (2014). Characterization of glucomannan from Amorphophallus oncophyllus and its prebiotic activity in vivo, Carbohydrate Polymers, 112, pp $475-479$

8. Herranz, B., Clara, A.T., Solo-de-zaldívar, B., and Borderias, A.J. (2013). Influence of Alkali and Temperature on Glucomannan Gels at High Concentration, LWT - Food Science and Technology, 51 (2), pp 50 - 500

9. Huang, Y., Chu, H., Huang, C., and $\mathrm{Wu}$, W. (2015). Alkali-Treated Konjac Glucomannan Film as a Novel Wound Dressing, Carbohydrate Polymers, 117, pp $87-778$

10. Jin, W., Mei, T., Wang, Y., Xu, W., Li, J., Zhou, B., and Li, B. (2014). Synergistic degradation of konjac glucomannan by alkaline and thermal method, Carbohydrate Polymers, 99, pp 270 277

11. Jin, W., Song, R., Xu, W., Wang, Y., Li, J., Shah, B.R., Li, Y., and Li, B. (2015). Analysis of deacetylated konjac glucomannan and xanthan gum phase separation by film forming, Food Hydrocolloids, 48, pp 320 - 326
12. Li, J., Ye, T., Wu, X., Chen, J., Wang, S., Lin, L., and Li, B. (2014). Preparation and Characterization of Heterogeneous Deacetylated Konjac Glucomannan, Food Hydrocolloids, 40, pp 9 - 15

13. Pan, Z., Meng, J., and Wang, Y. (2011). Particuology Effect of Alkalis on Deacetylation of Konjac Glucomannan in Mechano-Chemical Treatment, Chinese Society of Particuology, 9 (3), pp $69-265$

14. Solo-de-zaldívar, B., Tovar, C.A., Borderías, A.J., and Herranz, B. (2014). Food Hydrocolloids Effect of Deacetylation on the Glucomannan Gelation Process for Making Restructured Seafood Products, Food Hydrocolloids, 35, pp 59 - 68

15. Takigami, S. (2000). Handbook of hydrocolloids, Cambridge: Wood-head Publishing, pp 413-424.

16. Wardhani, D.H., Abdullah, Azizah, A.N, and Ananta, M.Y. (2016). Physicochemical properties of acetylated glucomannan of Amorphophallus onchophillus as excipient of drug controlled release, AIP Conference Proceedings, 1746, 020039 17. Wardhani, D.H., Puspitosari, D., Ashidiq, M.A., Aryanti, N., and Prasetyaningrum, A. (2017). Effect of Deacetylation on Functional Properties of Glucomannan, AIP Conference Proceedings, 1855, 030020

18. Wen, X., Cao, X., Yin, Z., Wang, T., and Zhao, C. (2009). Preparation and characterization of konjac glucomannan - poly ( acrylic acid) IPN hydrogels for controlled release, Carbohydrate Polymers, 78 (2), pp 193 198 
8 Simultaneous Effect Of Temperature And Time Of Deacetylation On Physicochemical Properties Of Glucomannan

19. Wen, X., Wang, T., Wang, Z., Li, L., and Zhao, C. (2008). Preparation of konjac glucomannan hydrogels as DNAcontrolled release matrix, International Journal of Biological Macromolecules, 42, pp $256-263$

20. Wenling, C., Duohui, J., Jiamou, L., Yandao, G., Nanming, Z., and Xiufang, Z. (2005). Effect of the Degree of Deacetylation on the Physicochemical Properties and Schwann Cell Affinity of Chitosan Films, Journal of Biomaterials Applications, 20, pp $157-176$
21. Zhang, C., Chen, J., and Yang, F. (2014). Konjac glucomannan, a promising polysaccharide for OCDDS, Carbohydrate Polymers, 104, pp 175 181

22. Zhang, T., Xue, Y., Li, Z., Wang, Y., and Xue, X. (2015). Effect of deacetylation of konjac glucomannan on Alaska Pollock surimi gels subjected to hightemperature $\left(120^{\circ} \mathrm{C}\right)$ treatment, Food Hydrocolloids, 14, pp $125-131$ 